\title{
Coordinating online health communities for cognitive and affective value creation
}

Citation for published version (APA):

Van Oerle, S., Mahr, D., \& Lievens, A. (2016). Coordinating online health communities for cognitive and affective value creation. Journal of Service Management, 27(4), 481-506. https://doi.org/10.1108/JOSM09-2015-0264

Document status and date:

Published: 01/01/2016

DOI:

10.1108/JOSM-09-2015-0264

Document Version:

Publisher's PDF, also known as Version of record

Document license:

Taverne

Please check the document version of this publication:

- A submitted manuscript is the version of the article upon submission and before peer-review. There can be important differences between the submitted version and the official published version of record.

People interested in the research are advised to contact the author for the final version of the publication, or visit the DOI to the publisher's website.

- The final author version and the galley proof are versions of the publication after peer review.

- The final published version features the final layout of the paper including the volume, issue and page numbers.

Link to publication

\footnotetext{
General rights rights.

- You may freely distribute the URL identifying the publication in the public portal. please follow below link for the End User Agreement:

www.umlib.nl/taverne-license

Take down policy

If you believe that this document breaches copyright please contact us at:

repository@maastrichtuniversity.nl

providing details and we will investigate your claim.
}

Copyright and moral rights for the publications made accessible in the public portal are retained by the authors and/or other copyright owners and it is a condition of accessing publications that users recognise and abide by the legal requirements associated with these

- Users may download and print one copy of any publication from the public portal for the purpose of private study or research.

- You may not further distribute the material or use it for any profit-making activity or commercial gain

If the publication is distributed under the terms of Article $25 \mathrm{fa}$ of the Dutch Copyright Act, indicated by the "Taverne" license above, 


\section{Coordinating online health communities for cognitive and affective value creation}

Cognitive and affective value creation

\author{
Marketing Department, Faculty of Applied Economics, University of Antwerp, \\ Antwerp, Belgium \\ Dominik Mahr \\ Department of Marketing and SCM and Service Science Factory, \\ Maastricht University, Maastricht, The Netherlands, and \\ Annouk Lievens \\ Marketing Department, University of Antwerp, Antwerp, Belgium
}

Sarah Van Oerle

\begin{abstract}
Purpose - The purpose of this paper is to develop a framework investigating patterns of online health communities. In particular, the study draws on coordination theory to identify four community configurations. Their distinct features determine communities' capacity to internalize and externalize knowledge, which ultimately determines their value creation in a service context.

Design/methodology/approach - The authors apply qualitative and quantitative techniques to detect similarities and differences in a sample of 50 online health communities. A categorical principal component analysis combined with cluster analysis reveals four distinct community configurations.

Findings - The analysis reveals differences in the degrees of cognitive and affective value creation, the types of community activities, the involved patients, professionals, and other stakeholders; and the levels of data disclosure by community members. Four community configurations emerge: basic information provider, advanced patient knowledge aggregator, systematic networked innovator, and uncomplicated idea sharer.

Research limitations/implications - The findings show that communities can be categorized along two knowledge creation dimensions: knowledge externalization and knowledge internalization. While, previous research remained inconclusive regarding the synergistic or conflicting nature of cognitive and affective value creation, the findings demonstrate that cognitive value creation is an enabler for affective value creation. The emerging configurations offer a classification scheme for online communities and a basis for interpreting findings of future services research in the context of online health communities. Originality/value - This research combines coordination theory with healthcare, service, and knowledge creation literature to provide a fine-grained picture of the components of online health communities. Thereby, inherent trade-offs and conflicts that characterize the components of coordination theory are investigated.
\end{abstract}

Keywords Value drivers, Health services, Services management, Service co-creation

Paper type Research paper

Patients increasingly use online services to gain insights into and share experiences about their health conditions. About 72 percent of US internet users seek health information online, and 16 percent of them search for peers who share similar health concerns (Pew Research Center, 2013). These searches for health information and peer-to-peer communication online are fueled by patients' struggle to satisfy their

The author would like to thank the Agency for Innovation by Science and Technology in Flanders (IWT) for its support.
Received 3 September 2015

Revised 1 February 2016

16 May 2016

Accepted 19 May 2016
7 April 2016 
JOSM 27,4

482

varied disease-related needs. When confronted with a diagnosis, patients often ask for explanations of the disease and treatment guidance ("cognitive value") but also want expressions of empathy or shared concern ("affective value") (Hoch and Ferguson, 2005; Johnson and Ambrose, 2006). The distinction is reflected in the services literature where consumers extract cognitive and affective value from their relationship with the service providers, both in an offline (Beatty et al., 1996; Gwinner et al., 1998), and an online setting (Dholakia et al., 2009; Mathwick et al., 2008). However, healthcare services considerably differ from any other service because they are often unwanted, although adherence to treatment can make a difference between life and death (Berry and Bendapudi, 2007). Time and budget constraints leave healthcare professionals only partly able to address diverse patient needs (LaVela and Gallan, 2014); doctors often schedule 11-minute time intervals for patient consultations, which suggests questionable healthcare quality (National Center for Health Statistics, 2012). The need for professional distance also prevents healthcare professionals from building overly empathic relationships with patients (Apesoa-Varano et al., 2011). Thus many patients leave their doctors' offices with an abundance of unanswered questions and insufficient opportunities to share their feelings (Johnson and Ambrose, 2006).

Because online health communities provide access to information and coordinate social interaction, they constitute an alternative solution for patients' needs, such that they likely improve the well-being of individuals and society as a whole (Zhao et al., 2015). In the online community patientslikeme.com, 300,000 members discuss more than 2,500 healthcare conditions (PLM, 2013). Such peer-to-peer interactions might complement traditional face-to-face encounters with medical professionals (Kivits, 2006). However, the diverse needs of different patients prevent any single, one-size-fits-all community; rather, cognitive and affective value in a community depends on who participates (e.g. patients, doctors, industry experts), the foundation of their relationship (e.g. trust, reciprocity), and their activities (e.g. sharing experiences, assessing new ideas, recommending alternative treatments). Many healthcare organizations struggle with the interdependencies and trade-offs across these components when they attempt to implement online services (Bain and Co., 2012; McKinsey and Co., 2014). The value propositions of online health communities highlight the creation of cognitive and affective value which aims at patient's well-being. A finer-grained understanding of the features offers community hosts insights how to tailor communities to various needs and market segments. Hence, this research adopts a provider perspective and investigates the different community features that determine the value proposition of an online health community.

This paper offers coordination theory, proposed by Malone and Crowston (1990), as a theoretical lens. Coordination theory has been applied in various research disciplines (e.g. computer science, sociology, political science, management science, systems theory, economics, linguistics, psychology) to examine collaborative systems. The four components of this theory (i.e. goals, activities, actors, and interdependencies) aid in capturing the complexity of coordinating online health communities. Thereby, the components provide a lens to examine the elements of online health communities and how they interact. Given the theory's particular focus on computer-supported cooperative work, the authors consider this framework as very suitable to examine the underlying mechanisms of online health communities. In this view, an online health community is a knowledge-based, cooperative system of value creation that relies on multiple community components to coordinate participants' interactions. These four components (i.e. goals, activities, actors, interdependencies) feature inherent trade-offs and conflicts. First, the goal of the community can be oriented toward cognitive and/or affective value creation. 
Prior healthcare research has established the importance of both dimensions for a patient's well-being, yet no agreement exists in terms of whether these components are synergistic or conflicting (Apesoa-Varano et al., 2011; De Valck et al., 2001). Second, community activities, such as information diffusion, social exchange, or idea development, demand different functionalities, motives, and skills (Nambisan and Nambisan, 2009). If a single community combines several activities, coordinative challenges arise for community management, which may hinder its ability to meet members' needs. Third, different actors or platform users might be targeted for participation. Greater diversity produces more diverse opinions, which enriches community content, but greater similarity ensures a common interest to facilitate communication (Phelps et al., 2012). Fourth, to manage online collaborations, several interdependencies between community members and their activities must be taken into account, such as trust-building mechanisms. The extent to which a community member discloses personal information may determine the level of trust among community members (Ebner et al., 2009) and thus the creation and sharing of valuable knowledge (Ridings et al., 2002). But community members likely are wary about sharing personal details, due to their privacy concerns (National Center for Health Statistics, 2012). In summary, the various, inherent conflicts noted in previous research prevent a single solution to emerge and instead demand subtle orchestration across these community components. This might explain why extant research on online peer-to-peer support has not reached a consensus regarding its effects on health and social outcomes (Eysenbach et al., 2004).

The authors probe the heterogeneous nature of health communities by investigating the community components driving cognitive and affective value creation. The focus is on the characteristics of communities in which patients interact, and thus the authors strive for three main contributions. First, this paper sheds light on the diverse landscape of digital service provision in the healthcare industry by identifying clusters of value creation for patients in digital communities. In doing so, the authors contribute to a key services research priority by providing insights into the coordination of value co-creation in a collaborative context (Ostrom et al., 2015). Through the lens of coordination theory, the authors systematically compare and describe online health communities and their features. Thereby, four clusters are identified with distinct community components (i.e. goals, activities, actors and interdependencies) that determine their potential for cognitive and affective value creation. Categorical principal component analysis is well-suited for investigating complex social phenomena such as online health communities to detect similarities and differences among them (Jick, 1979; Odekerken-Schröder et al., 2010). Second, the authors advance research on the relationship between cognitive and affective value created in a digital setting and its drivers. Cognitive and affective value represent key dimensions of patients' knowledge (Apesoa-Varano et al., 2011; De Valck et al., 2001), but research on their simultaneity in healthcare is scarce. However, a distinct characteristic of healthcare services in comparison with other services is the customer's need for a "whole person" service. Hence, simultaneous addressing both cognitive and affective needs (Berry and Bendapudi, 2007). This research attempts to shed light on their synergistic or conflicting nature, to determine which community features affect them. Accordingly, the authors advance coordination theory by considering not only cognitive and relational goals but also affective goals of coordinating an online health community and theoretical components that coincide with both types of goals. In doing so, this study investigates the development of technology-enabled services to improve patients' well-being, thereby contributing to transformative service research (Ostrom et al., 2015).
Cognitive and affective value creation 
JOSM

27,4

484

Third, the authors probe the inherent trade-offs that characterize key components of coordination theory in the context of online communities. By identifying clusters of communities, a better understanding of the different characteristics and interdependencies among and within components is obtained. On a broader level, this research advances service managers' understanding of how empowered patients might contribute to value creation and of the role of online communities in the healthcare service system which is identified as a service research priority by Ostrom et al. (2015).

To achieve these contributions, the paper starts with a literature review on patient involvement, online health communities, and coordination theory. Next, the authors describe the methodology, identify clusters of health communities, and elaborate on their features. Finally, the authors discuss the findings, formulate key implications for theory and practice, and offer suggestions for further research.

\section{Literature review}

Involvement of patients in healthcare services

The healthcare landscape traditionally has been dominated by five stakeholders regulators, providers, payers, suppliers, and patients - among which patients had the least power (Stremersch, 2008). Technological advances prompted a shift from a healthcare model dominated by professionals toward a patient-centered model, in which patients and professionals collaborate to create a service that provides the most optimal healthcare solution for each case (Camacho et al., 2009). This new paradigm of patient empowerment entails "an enabling process through which individuals or groups take control over their lives and managing disease" (Demiris, 2006, p. 186). As an illustration of its emergence, a recent study shows that 13 percent of US healthcare customers maintain electronic health records, independent of their doctors' (Deloitte, 2014). The increasing involvement of patients as active participants in their treatment choices is part of a global marketplace trend toward customer participation (Prahalad and Ramaswamy, 2004a; Vargo, 2008), such that the customer is no longer a passive recipient of services but rather serves as an active co-creator of value. Firms thus need to offer active customers opportunities to engage in extensive value co-creation (Jaakkola and Alexander, 2014). Despite the emergence of patient value co-creation as a key service research priority (Ostrom et al., 2015), few studies investigate how online communities can be coordinated and thereby serve as platforms for patient involvement (Zhao et al., 2015). Yet, the collaborative context of value co-creation, which is increasingly characterized by multi-actors and networks, adds to its complexity and asks for a significant coordination effort. Hence, more research is needed to clarify how coordination should take place (Ostrom et al., 2015).

Digital services provide healthcare customers with easy access to healthcare information and facilitate peer-to-peer connections so they can exchange experiences and social support (Cline and Haynes, 2001). Shared information may serve as input for the patient-professional encounter, such that it might encourage active patient involvement during service delivery and foster shared decision making (Gustafson et al., 1999; McColl-Kennedy et al., 2012; Sweeney et al., 2015). Previous research also concludes that patient involvement leads to favorable outcomes, such as more trust in the health professional, higher patient satisfaction, better adherence to treatment, and overall increased health status (Camacho et al., 2009).

\section{Online health communities}

Online communities gather individuals who interact on a common interest, facilitated by a technical platform (Lee et al., 2003; Leimeister et al., 2006; Mahr and Lievens, 2012). 
Research regarding online health communities can be classified around the components of coordination theory, hence goals, activities, actors, and interdependencies (see Table I). While previous research mainly focusses on one component of coordination theory, this study aims to provide an overview of the components including their respective trade-offs.

Online health communities drive customer involvement through information provision, knowledge creation, and connections to peers. Firms in various sectors, including high-tech (e.g. Dell), toys (e.g. Lego), and automotive (e.g. Fiat), rely on online communities to enhance customer involvement. Yet online health communities are unique. These customers are often ill and discuss services they need but do not want (Berry and Bendapudi, 2007). Therefore, they tend to contain more affective content than online discussions in other sectors. Furthermore, the creation of trust is crucial (Ebner et al., 2004); discussing life-threatening diseases or health-related taboos demands trust in other members' competence and goodwill.

In online health communities, patients share information with peers, who then process that information in light of their existing stock of knowledge. Through discussions of their interpretations in the online community, they create new knowledge (Bagozzi and Dholakia, 2002; Nonaka, 1994). Established social relationships with peers then provide trust and nurture future information sharing and knowledge creation (Ridings et al., 2002). This is in line with research that focusses on relational coordination, or the role relationships play in the process of coordination (Gittell, 2002). This research stream states that strong relationships between community members fosters them to effectively coordinate activities since they share mutual goals, respects each other's contributions and share knowledge.

\begin{tabular}{|c|c|c|c|}
\hline Classification & Theme & Authors & \\
\hline Goals & $\begin{array}{l}\text { Health outcomes } \\
\text { Patient-provider } \\
\text { relationship } \\
\text { Integration online and } \\
\text { offline services } \\
\text { Perceived } \\
\text { (dis)advantages }\end{array}$ & $\begin{array}{l}\text { Turner } \text { et al. (2001), Colvin et al. (2004), Eysenbach et al. } \\
\text { (2004), Kivits (2006), McMullan (2006), Stevenson } \text { et al. } \\
\text { (2007), Dannecker and Lechner (2007), Fang et al. (2008), } \\
\text { and Keeling } \text { et al. (2015) }\end{array}$ & \\
\hline Activities & $\begin{array}{l}\text { Innovation } \\
\text { Knowledge creation } \\
\text { Information provision } \\
\text { Connections to peers }\end{array}$ & $\begin{array}{l}\text { Cline and Haynes (2001), McMullan (2006), Nambisan and } \\
\text { Nambisan (2009), Adams (2011), Bullinger et al. (2012), } \\
\text { Vicdan and Dholakia (2013), and Zhao et al. (2015) }\end{array}$ & \\
\hline Actors & $\begin{array}{l}\text { Impact of participant } \\
\text { characteristics } \\
\text { Motives for } \\
\text { participation } \\
\text { Precursors for } \\
\text { relationship } \\
\text { formation } \\
\text { Types of actors }\end{array}$ & $\begin{array}{l}\text { Leimeister et al. (2006, 2008), Mo et al. (2009), and } \\
\text { Welbourne et al. (2013) }\end{array}$ & \\
\hline Interdependencies & $\begin{array}{l}\text { Trust-building } \\
\text { mechanisms } \\
\text { Quality assurance } \\
\text { procedures } \\
\text { Design issues } \\
\text { Social practices }\end{array}$ & $\begin{array}{l}\text { Cline and Haynes (2001), Leimeister et al. (2005), Maloney- } \\
\text { Krichmar and Preece (2005), and Loane and D'Alessandro } \\
\text { (2013) }\end{array}$ & $\begin{array}{r}\text { Table I. } \\
\text { State-of-the-art } \\
\text { online health } \\
\text { community research }\end{array}$ \\
\hline
\end{tabular}

Cognitive and affective value creation 
JOSM

27,4

Hence, online health communities constitute knowledge creation communities, with knowledge defined as "information that is relevant, actionable, and based at least partially on experience" (Leonard and Sensiper, 1998, p. 113). Explicit knowledge is codified and transmittable in formal language; tacit knowledge has a personal quality, which makes it hard to formalize and communicate (Nonaka, 1994). Online health communities facilitate the interplay between explicit and tacit knowledge by providing tools to externalize tacit knowledge and internalize explicit knowledge.

Interactions in a community might involve different healthcare stakeholders, including regulators, providers, payers, suppliers, and healthcare customers (e.g. patients, families, informal caregivers), and in general they center on brands, products, and services (McWilliam, 2012). The common interest, which provides the community's main reason to exist, relates to healthcare activities such as patient or staff education, providing support, discussion of diseases and treatments, sharing of documents, or consulting with experts (Demiris, 2006). In summary, online health communities are online services that employ social technologies and tools to enable knowledge among healthcare stakeholders. For this research, the authors focus on patient-centered communities in which patients extract value in the form of new knowledge, created by discussing information shared in the community. Still, other healthcare stakeholders, beyond patients, might participate in the community, by adding specialized knowledge or to learn from patients.

\section{Cognitive and affective value creation}

Patients process and interpret information shared online. Through social interaction and discussion, they create value in the form of new knowledge for patients (Dholakia et al., 2009), as either cognitive and affective value (Chronister et al., 2006; Zainuddin et al., 2013). First, cognitive value relates to facts, advice, and guidance that support patients' knowledge about health-related issues. Better informed and more knowledgeable patients are more inclined to take an active role in their healthcare management and implement their treatments (Camacho et al., 2009). These patients may benefit from their active involvement in decision-making processes, because the chosen therapy will better fit their treatment and desired outcomes, which should improve their general health status (Camacho et al., 2009). Second, affective value relates to affection, listening, and empathy (De Valck et al., 2001; Ong et al., 1995), which expands patients' knowledge by helping them vent their feelings, bear the burden of the disease, and cope with the resulting stress (Apesoa-Varano et al., 2011). This value can evoke optimistic self-beliefs in patients, be beneficial for recovery, and encourage patients to cope with discomfort or relapses (Schulz and Schwarzer, 2004). Hence, cognitive and affective value creation constitutes the foundation of an online community's value proposition. This is in line with literature on the patient-physician relationship that states that patients experience a need for cognitive value (i.e. need to solve the illness problem) and affective value (i.e. need for emotional support). To satisfy these needs the physician should perform instrumental tasks such as prescribing medication and exchanging information as well as display affective behavior such as the expression of empathy and reassurance (Roberts and Aruguete, 2000). Thereby, affective value is linked to affection, listening, and empathy while cognitive value relates to facts, advice, and guidance that support patients' knowledge about health-related issues (Beatty et al., 1996; Gwinner et al., 1998). Since online health communities complement the task of the physician, similar goals are identified as value proposition. 
The complexity of digital services, which involve various processes of interaction among different actors, demands a more fine-grained view of value creation in online communities (Chandler and Lusch, 2015). The authors use coordination theory as the affective value creation theoretical lens as it has been used to describe computer meditated environments coordinating large groups such as universities and government (Euerby and Burns, 2014). In line with this theory online health communities are conceptualized as complex service systems that hinge on four components.

The first component, goals, relates to a community's objectives, namely, creating cognitive and affective value for patients. The outcome of participation in an online community is a new stock of knowledge that patients can use to deal with their disease. To combine information in the community with their preexisting knowledge base, patients interpret information, discuss it online, and create value in the form of a new stock of knowledge, which is either cognitive and affective oriented (Nambisan and Nambisan, 2009). Cognitive value is connected to knowledge which helps patients better understand their disease and learn about new treatments. Affective value consists of knowledge which helps patients bear the burden of the disease and cope with stress (Apesoa-Varano et al., 2011). Both value dimensions must be present and coordinated in the online community, but they can be both synergistic or conflicting (Apesoa-Varano et al., 2011; De Valck et al., 2001).

The second component, activities, relates to different practices that contribute to the goals of cognitive and affective value creation. Knowledge creation is a social rather than an individual process (Bagozzi and Dholakia, 2002), so health communities need activities in place to support social interaction, which leads to knowledge creation. Sharing information about the community status, such as the most popular topics, draws members to relevant content that can function as a building block for further knowledge creation. Community hosts might help patients connect by providing online tools, such as forums and chat sessions that encourage patients to share data (Lee et al., 2003). Community members might directly or indirectly contribute, to the benefit of third parties. For example, a healthcare provider who carefully listens to patient-provided information can obtain a better understanding of patient needs and ultimately innovate products and services that better meet these consumers' requirements (Prahalad and Ramaswamy, 2004a). Knowledge creation among peers also fosters usage intentions for the resulting service innovations (Kleijnen et al., 2009). However, diverse patient needs, interests, and skills related to social interaction and knowledge creation require the careful coordination of activities.

The third component describes actors in the online health community. Although the authors' focus is on patient-centered communities, other actors may be active in the community too (Kuenne et al., 2013). Increasing the diversity of actors, by adding doctors and other healthcare stakeholders, might foster the exchange of diverse, rather than redundant, knowledge and increase learning opportunities (Dahlin et al., 2005). However, diversity should be balanced with perceived similarity among actors, to increase common understanding of the community content and coordinate interactions (Ren et al., 2007).

The final component, interdependencies among actors and their activities, entails the conflict of trust vs privacy. Especially in a healthcare context, trust is required to put people at ease and allow them to share personal details (Bansal et al., 2010). Privacy issues, and especially the loss of control over health data, are central 
JOSM

27,4

concerns for sharing healthcare information online (Bansal et al., 2010). However, this concern might be mitigated by coordinating trust-building mechanisms, such as self-disclosure. The extent to which a community member discloses personal information largely determines the level of trust created among community members (Ebner et al., 2009) and thus knowledge sharing and creation (Ridings et al., 2002). Furthermore, personal information reveals the level of similarity among members (i.e. homophily), which can foster collaboration among similar patients (McPherson et al., 2001).

\section{Methodology \\ Overview}

This research combines qualitative and quantitative approaches (Jick, 1979; Odekerken-Schröder et al., 2010). The authors start with a qualitative, in-depth analysis of online communities, then contrast these insights with existing literature and develop a coding scheme to differentiate among communities. By applying this coding scheme across relevant communities, the authors quantify their insights, detect similarities and differences, and map clusters of communities in a two-dimensional space. By combining qualitative and quantitative techniques this research approach is able to reduce the pitfalls of both methods. In the following paragraphs the authors provide an in-depth overview of the data analysis steps. Similar approaches have proven helpful in studying heterogeneous patterns in complex research phenomena (Moeller et al., 2013; Odekerken-Schröder et al., 2010).

\section{Sample}

With a comprehensive, systematic internet search, via Google's and Yahoo's search engines (i.e. search terms: "online health community," "healthcare forum," "cancer community," "diabetes forum," etc.), together with expert consultations (i.e. physicians and business consultants), a sample of 63 English-language online health communities was constructed. Saturation was reached when similar set-ups (i.e. information sites with forums attached), topics (i.e. general communities vs specific communities) and objectives (i.e. informing patients) came back. The sample to 50 communities was reduced by selecting those with public access (i.e. not restricted to a particular type of stakeholders, such as patients or doctors), some degree of interaction (i.e. supported interactions among members), and recent activities. In the sample, 21 communities focus on specific health topics, and the remaining 29 focus on health in general. An overview of the selected communities is provided in the Table AI.

\section{Data analysis}

In the analysis of the 50 communities, the authors undertook two three-stage processes (see Table II). In the first phase, qualitative analysis techniques were used to develop a coding scheme (Stage 1), code each community accordingly (Stage 2), and interpret the results (Stage 3). Then in the second phase, using quantitative analysis techniques, the authors performed a categorical principal components analysis (CATPCA) to obtain a bidimensional spatial representation of the coded communities (Stage 4), applied hierarchical cluster analysis to explore potential clustering possibilities in this space (Stage 5), and analyzed and interpreted cluster memberships for the most appropriate solution through k-means cluster analysis (Stage 6) (Moeller et al., 2013; Odekerken-Schröder et al., 2010). 


\begin{tabular}{|c|c|c|c|c|}
\hline Phase & Stage & Objective & Main techniques & Cognitive and \\
\hline \multirow[t]{3}{*}{$\begin{array}{l}\text { Qualitative } \\
\text { analysis }\end{array}$} & 1 & Develop a coding scheme & \multirow{4}{*}{$\begin{array}{l}\text { Categorization, } \\
\text { abstraction, comparison, } \\
\text { iteration } \\
\text { Comparison, } \\
\text { dimensionalization, } \\
\text { integration, } \\
\text { Integration, iteration } \\
\text { CATPCA }\end{array}$} & creation \\
\hline & 2 & Code 50 communities & & 489 \\
\hline & 3 & Interpretation of coding results & & \\
\hline \multirow[t]{3}{*}{$\begin{array}{l}\text { Quantitative } \\
\text { analysis }\end{array}$} & 4 & $\begin{array}{l}\text { Identify meta-categories for categorical principal } \\
\text { component analysis and obtain object scores for a } \\
\text { bidimensional representation of the coded } \\
\text { communities }\end{array}$ & & \\
\hline & 5 & $\begin{array}{l}\text { Use the object scores obtained in Stage } 4 \text { to explore } \\
\text { clustering possibilities }\end{array}$ & $\begin{array}{l}\text { Hierarchical cluster } \\
\text { analysis }\end{array}$ & Table II. \\
\hline & 6 & $\begin{array}{l}\text { Determine the most appropriate cluster solution, } \\
\text { analyze and interpret it }\end{array}$ & K-means cluster analysis & $\begin{array}{r}\text { Data analysis phases } \\
\text { and stages }\end{array}$ \\
\hline
\end{tabular}

\section{Qualitative analysis}

In Stage 1 of the qualitative analysis, deductive (derive meta-categories from theory) and inductive (derive community components from data) strategies were combined to develop a coding scheme. To analyze the data set of 50 online communities, the authors used a systematic approach as formulated by Corbin and Strauss (2015). In a first step, open coding is applied which means that the authors did not establish a coding scheme upfront, but rather let the codes emerge during the coding process. Online communities were defined as unit of analysis and labeled with relevant codes that reflected the research questions, thereby staying as close to the data as possible (Spiggle, 1994). Accordingly, the 50 communities were labeled as belonging to certain empirical categories (e.g. presence of community statistics). In doing so, the authors applied the fundamental, basic qualitative data manipulation operations defined by Spiggle (1994): categorization (classifying units of data) and comparison (exploring differences and similarities across incidents). In a second step, axial coding is applied which means that the concepts identified through open coding are related to each other through comparative analysis. Thereby the empirical categories (e.g. presence of community statistics) were combined into higher-order conceptual constructs (e.g. simple way of sharing information about the community) (Spiggle, 1994) through basic operations such as abstraction (creating higher-order conceptual constructs) and integration (of categories and constructs). In a third step, the community components, derived from data are combined with the meta-categories, deduced from theory. The four metacategories from coordination theory appeared in the data set: goals (i.e. cognitive and affective value), activities (community situation, data transformation, data integration, and innovation intention), actors (platform users), and interdependencies (selfdisclosure). During Stage 2, two independent coders reviewed the data set of 50 communities and resolved any differences through discussion. Intercoder reliability was calculated for each of the components by Krippendorff's $\alpha$ (goals: cognitive value: $\alpha=0.80$; affective value: $\alpha=0.92$, community situation: $\alpha=0.83$, data transformation: $\alpha=0.90$, data integration: $\alpha=0.90$, innovation intention: $\alpha=0.83$, platform users: $\alpha=0.92$, self-disclosure: $\alpha=0.96$ ) (Hayes and Krippendorff, 2007). In Stage 3, the categories and constructs were integrated and iteration was used to go back and forth between several research stages, to support induction and deduction (Spiggle, 1994). 
JOSM

27,4

490

\title{
Quantitative analysis
}

For a more complete understanding of the dimensionality of online health communities, the qualitative phase was complemented with a quantitative phase (i.e. triangulation) (Denzin, 1970). In Stage 4, the authors conducted a special principal component analysis, known as CATPCA, which includes a nonlinear optimal scaling transformation of the meta-categories. Hence, complex, multivariate data can be analyzed that include nominal, ordinal, and numerical variables. In this way, CATPCA enabled us to capture the heterogeneous nature of online health communities. The authors imposed a two-dimensional solution on the data in order to obtain a parsimonious representation in the form of a bi-plot. The authors recoded the categories in the qualitative phase into categorical variables (Odekerken-Schröder et al., 2010), performed CATPCA, and obtained two dimensions, along with the object scores for each community on each dimension. Thereby, the object scores reflect how each of the 50 communities score on the two dimensions identified. Then in Stage 5, the authors conducted a hierarchical cluster analysis, using the standard squared Euclidian distance in combination with Ward's criterion. The object scores served as cluster variables. The authors checked multiple cluster solutions and decided - based on the output of the agglomeration schedule - that a four-cluster solution emerged as strongest on a conceptual level. This decision was based on the even distribution of communities over clusters and whether the communities bundled in clusters could be easily labeled in line with existing theory. In Stage 6, the authors conducted a fourmeans cluster analysis of the object scores of the CATPCA based on the iterate and classify method. Thereby four clusters of online health communities were identified, according to the two CATPCA dimensions. Crosstabs with a $\chi^{2}$ test were constructed to support the description of the community clusters and bootstrapping was performed to confirm the robustness of the found four-cluster solution.

\section{Results}

Qualitative phase

During the qualitative analysis of the communities, the authors identified four metacategories that reflect the components of coordination theory, in the context of online health communities (see Table III).

The first component, goals, captures the cognitive and affective knowledge created in online health communities. By scanning the mission statements and community content, the focus of the community was identified as cognitive, affective, or mixed, in terms of the value creation it intended to support. For example, the mission statement of MDJunction.com starts by noting that "group participation can offer emotional

\begin{tabular}{lll}
\hline Meta-categories & Community components & Frequency \\
\hline \multirow{2}{*}{ Goals } & Cognitive value & No: 2, Low: 6, Medium: 9, High: 33 \\
& Affective value & No: 19, Low: 6, Medium: 12, High: 13 \\
Activities & Community situation & No: 8, Simple: 16, Moderate: 16, Advanced: 10 \\
& Data transformation & Low: 22, Medium: 21, High: 7 \\
& Data integration & Anecdotal: 35, Structured: 8, Mixed: 7 \\
& Innovation intention & No innovation: 30, Innovation: 20 \\
Actors & Platform users & Patient: 34, Patient and experts: 9, patient and others: 7 \\
Interdependencies & Self-disclosure & No: 18, Low: 17, Medium: 8, High: 7
\end{tabular}

Table III.

Coordination theory in online health communities

\begin{abstract}
Interdependencies Self-disclosure
\end{abstract}
No: 2, Low: 6, Medium: 9, High: 33

No: 19, Low: 6, Medium: 12, High: 13

Anecdotal: 35, Structured: 8, Mixed: 7

o innovation: 30, Innovation: 20

No: 18, Low: 17, Medium: 8, High: 7 
support, confidence, and strength; can foster hope and can lead to improved coping," suggesting that this community host aims for affective value. However, the content in the community mainly pertains to cognitive value, so the final coding was a mixed community, with medium levels of cognitive and affective value. That is, the mission statement provides an initial starting point, but community content was used to make the final judgment of the community's goal. In online health communities, patients create cognitive value by providing information in their online profiles and sharing their experiences in online support forums, which offer a basis for discussion and new knowledge creation. Affective value is provided as communication in online support forums, blogs, and chat rooms. Despite a lack of socio-demographic or visual cues, trusting, emotion-oriented relationships can develop in online contexts, though they might take longer (Wilson et al., 2006). The goals component was operationalized with two categorical variables, cognitive, and affective value, which range from no to low to medium to high (Table IV). Two trained coders received the mission statement of the community together with a random selection of 50 online postings. A detailed description of the definitions of cognitive and affective value allowed them to assess the cognitive and affective goals of the online health community.

The second component, activities, relates to the community situation, data transformation, data integration, and innovation intentions. First, sharing updates about the community situation reveals information about the community and what content is currently thriving. For example, in Germtrax.com, the community host aggregates member data and provides it to the community as graphs and reports regarding disease outbreaks (Germtrax, 2012). Different information sharing methods were categorized according to how much effort they demand from the community host, from no/low (e.g. sharing community statistics, highlighting popular content) to moderate (e.g. presenting word clouds and topic tags) to advanced (e.g. sharing discoveries based on member data) (see Table IV). Second, data transformation occurs through tracking and health data visualization tools, forums, and blogs. For example, the data-driven patientslikeme.com community provides tools for patients to visualize their health data daily (PLM, 2013), which encourage them to reflect on their health situation and transform their existing knowledge in data that might be shared online. Several communities also were dedicated to collecting patients' reviews of products (e.g. drugs, vitamins, supplements), doctors, or hospitals. These community tools aim to transform patients' existing knowledge, gained from their experiences with healthcare offerings, into online content that might be shared and spark new knowledge creation. This categorical variable was operationalized as low (i.e. one type of data transformation provided), medium (two or three types of data transformation), or high (four or five types of data transformation) (Table IV). Third, data integration refers to how different data sources get integrated into the community. Consider, for example, the patients' profiles on patientslikeme.com, which encourages them to update their health status with exact facts and numbers that then can be aggregated and shared with community members in the form of graphs and figures (PLM, 2013). In addition to this structured integration of patients' data, patientslikeme.com provides forums and opportunities to send personal messages, such that patients can discuss their disease in narratives, which allow for more rich and detailed content and discussions (PLM, 2013), in which patient data are mostly anecdotal. Data integration was coded categorically as structured (i.e. systematic graphs and figures), anecdotal (stories and narratives), or mixed (Table IV). Fourth, patients can be involved in different sequential stages of the
Cognitive and affective value creation 
JOSM

27,4

492 \begin{tabular}{ll}
$\begin{array}{l}\text { Community } \\
\text { components }\end{array}$ & $\begin{array}{l}\text { Frequency } \\
(n=50)\end{array}$ \\
\hline
\end{tabular}

Discretizing rule

\section{Community situation \\ No community situation \\ Simple \\ 8 No criteria \\ 16 Criteria 2-5}

1. No community situation

2. Sharing community stats

3. Highlight top content

4. Highlight popular content/hot topics

5. Highlight recent topics

Moderate

16 Criteria 6-9

Advanced

10 Criteria $10-11$

Data transformation (DT)

Low

Medium

High

Only 1 type of DT Types of DT: Discussion forum, Member 2 or 3 types of DT blog, Chat, Q\&A with peers, Personal 4 or 5 types of DT Messages, Health tracking and sharing, Review tools, Data sharing \& health geography, Polls \& quick questions \& surveys, Ask a doctor

35

8

7

30 No innovation intention

20 Innovation intention: Idea sharing, reviews, share health data, health geography, clinical trials

7. Overview group members

8. Tagging

9. Top contributors

10. Presenting aggregated community data

11. Share discoveries based on member data

$18 \quad$ No

Table IV.

Discretized variables Medium

in the categorical principal components High analysis

User

Patients

Patients and experts

Patients and other

stakeholders

Self-disclosure

No

Low

Data integration

No innovation intention
No Low: socio-demographic profile information (e.g. age, gender, location, picture)

Medium: low profile information plus general information about their disease (e.g. type of disease, health interests)

High: medium profile information plus more detailed information about his condition (e.g. treatment plans and drugs)

innovation process, such as ideation, development, prototyping, and testing (Mascarenhas et al., 2004; Verma et al., 2012). If patients are involved in the ideation stage, the community host formulates a predefined innovation challenge, and patients give their opinion and potential solutions. For example, in innovationbyyou. com, the host, which develops ostomy and incontinence appliances, probes patients' experiences with difficult-to-open packaging and potential solutions to make life 
easier (Innovationbyyou, 2013). Another approach lets patients formulate their own challenges. In gemeinsamselten.de, patients with rare diseases can formulate problems and present them to a variety of community members (Gemeinsamselten, 2012). In the development phase, community members might discuss ideas in online forums to develop a concept from the initial idea, describing the technology, working principles, and form of the product or service. Once it reaches the prototyping phase, innovationbyyou.com involves members by providing them with toolkits to develop a mock-up of their optimal incontinence product (Innovationbyyou, 2013). The authors also find evidence of patient involvement in the testing phase of innovation, in the form of clinical trials. Patients who are active in online health communities are highly engaged and knowledgeable about their disease, easy to reach, and eager to participate in scientific activities. Innovation intention thus is operationalized as a dichotomous variable: no innovation intention vs innovation intention (see Table IV).

The third component, actors, consists of different participants who play an active role in the online health community. Although the authors focus on patient-centered communities, they also noted that several online health communities employ doctors to answer patient questions or act as moderators in online discussions. Several other healthcare stakeholders might play important roles or add specific knowledge, such as pharmaceutical companies, developers of medical devices, and research institutions. In the online community patientopinion.org, patients provide feedback about their experiences with healthcare services in UK hospitals. Their remarks get transferred to the hospital under review, and several stakeholders (e.g. nurses, specialists, administrative staff) respond by describing how the patient's feedback led to service improvements (PatientOpinion, 2013). This categorical variable was operationalized as only patients, patients and experts, or patients and other stakeholders (Table IV). Hereby, "experts" refers to doctors, nurses and healthcare specialists, while "other healthcare stakeholders" consists of pharmaceutical industry representatives, and research institutions.

The final component, interdependencies, captures the level of self-disclosure offered by the platform, not the personal choice of presentation by the patient. That is, this paper examines the characteristics of online communities, rather than the characteristics of its members. A low level of self-disclosure involves sociodemographic information (e.g. age, gender, location, picture), which has a limited impact on trust building. At the medium level, participants add general information about their disease (e.g. what type of disease, health interests). The highest level of self-disclosure means that participants add detailed information about their condition (e.g. treatment plans, drugs) (Table IV).

\section{CATPCA dimensions: knowledge internalization and knowledge externalization}

In Stage 1 of the analysis, four meta-categories were identified in the data set: goals (i.e. cognitive and affective value), activities (community situation, data transformation, data integration, innovation intention), actors (platform users), and interdependencies (self-disclosure). In Stage 4, only activities, actors, and interdependencies were considered to perform the CATPCA, because these meta-categories describe how goals get accomplished. Furthermore, because cognitive and affective value are the main knowledge outcomes of online health communities, they are explicitly linked to the resulting clusters from the CATPCA.

The authors computed ordinal variables related to the underlying categories (see Table IV). Two CATPCA dimensions resulted from these categories, so an object score was calculated for each community in the data set on each dimension.
Cognitive and affective value creation 
JOSM

27,4

494

The first dimension retrieved from CATPCA comprises sharing the community situation, data integration, innovation intention, and user type, which is summarized under the heading knowledge internalization. The second dimension consists of data transformation and self-disclosure, which is labeled knowledge externalization. Both dimensions coincide with Nonaka's (1994) knowledge creation framework. They achieve eigenvalues greater than 1 and sufficient reliability for exploratory research (Cronbach's $\alpha=0.928$ ); they account for 73 percent of total variance (Table V).

Knowledge internalization refers to tools that support people's learning by transforming their explicit knowledge into tacit knowledge (Nonaka, 1994); it integrates community situation, data integration, innovation intention, and user type. Sharing the community situation pertains to whether the community host explicitly shares information from within the community, such as community statistics, topic word clouds, or discoveries derived from member data. Communicating such information facilitates the internalization of knowledge created in the community by drawing attention to interesting content. Data integration involves the combination or integration of information sources held by different members, which then leads to more knowledge (Nonaka, 1994), whether in a structured or a more anecdotal way (Vicdan and Dholakia, 2013). Both routes stimulate knowledge internalization, though through different mechanisms. That is, structured data integration provides a clear overview of information and stimulates cognitive focus; anecdotal data integration instead supports cognitive processing through writing-as-thinking (Menary, 2007). An innovation intention implies the presence of tools that include patients in several innovation steps, ranging from ideation to testing. These tools invite them to learn from one another and use their knowledge for innovation purposes (Swan, 2009), such that community members internalize the tacit knowledge of their peers. Finally, user type refers to who is using and internalizing the knowledge created in the community, whether patients alone, with experts (doctors, nurses, healthcare specialists), or with other healthcare stakeholders (pharmaceutical industry representatives, research institutions) who learn from the interactions with patients.

Knowledge externalization refers to tools that help members transform their tacit knowledge into explicit knowledge (Nonaka, 1994), which include data transformation and self-disclosure. Data transformation relates to individual interactions to externalize tacit knowledge so that others may use it as well (Nonaka, 1994). Online health communities feature different tools to facilitate data transformations, such as discussion forums, health tracking, and short surveys to encourage knowledge externalization.

\begin{tabular}{lccr}
\hline Categorical variable & Dimension 1 & Dimension 2 & Total \\
\hline Community situation & 0.839 & 0.245 & \\
Data transformation & -0.271 & 0.869 & \\
Data integration & 0.862 & 0.097 & \\
Innovation intention & 0.819 & -0.070 & \\
User type & 0.729 & -0.082 & 0.928 \\
Self-disclosure & 0.069 & 0.918 & 4.408 \\
Cronbach's $\alpha$ & 0.760 & 0.485 & 73.466 \\
Total variance (eigenvalue) & 2.728 & 1.680 & \\
Percentage of variance & 45.473 & 27.993 &
\end{tabular}

Table V. CATPCA results
Notes: The values in the first six lines are the factor loadings. The italic values indicate that the variable was assigned to the respective dimension 
The level of self-disclosure depends on the patient's online profile (Leimeister et al., 2005). More advanced profile possibilities (e.g. detailed disease information, treatment plans, drugs) contribute more to knowledge externalization.

\section{Clusters}

The fifth stage of the empirical analysis establishes the number of clusters. A fourcluster solution emerged as empirically balanced and conceptually strong. In the sixth stage, the authors established optimal cluster membership, such that each community was allocated to one of the four clusters. In Figure 1, the four-cluster solution that resulted from the average object score on each of the four meta-categories is presented (Table VI).

Cluster 1 features simple sharing of information about the community situation, a medium level of data transformation, and anecdotal data integration. They tackle any conflicts about how to manage different activities by providing a basic level for each activity. Furthermore, they focus on one type of user, the patient, to increase common understanding of the community content. Similar backgrounds and mindsets facilitate their communication and may foster future participation in the community (McPherson et al., 2001). These communities support only a low level of self-disclosure, mostly focussed on sociodemographic information. For example, Inspire.com provides online support for patients by allowing them to share their stories and experiences (Inspire, 2014). The authors refer to this cluster as basic information providers.

Cluster 2 exhibits moderate levels of sharing with regard to the community situation, combined with a high level of data transformation and anecdotal data integration.

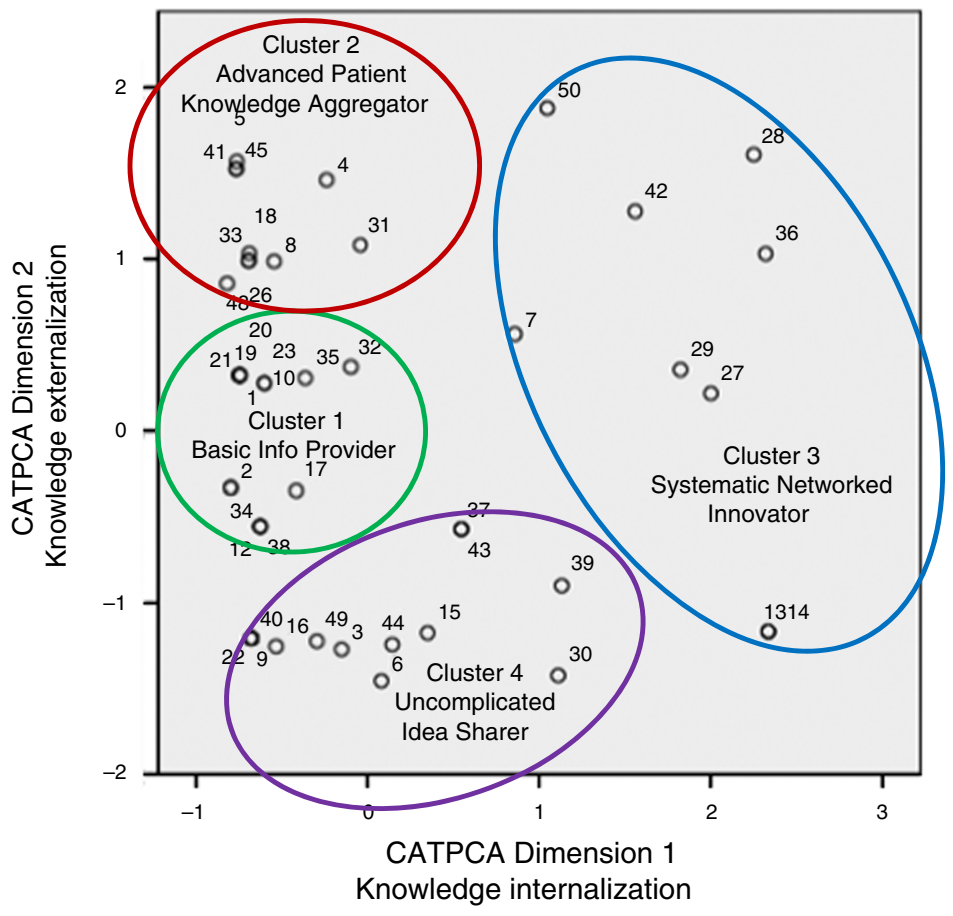

Figure 1. Community clusters in the CATPCA dimensions bi-plot
Cognitive and affective value creation

495 


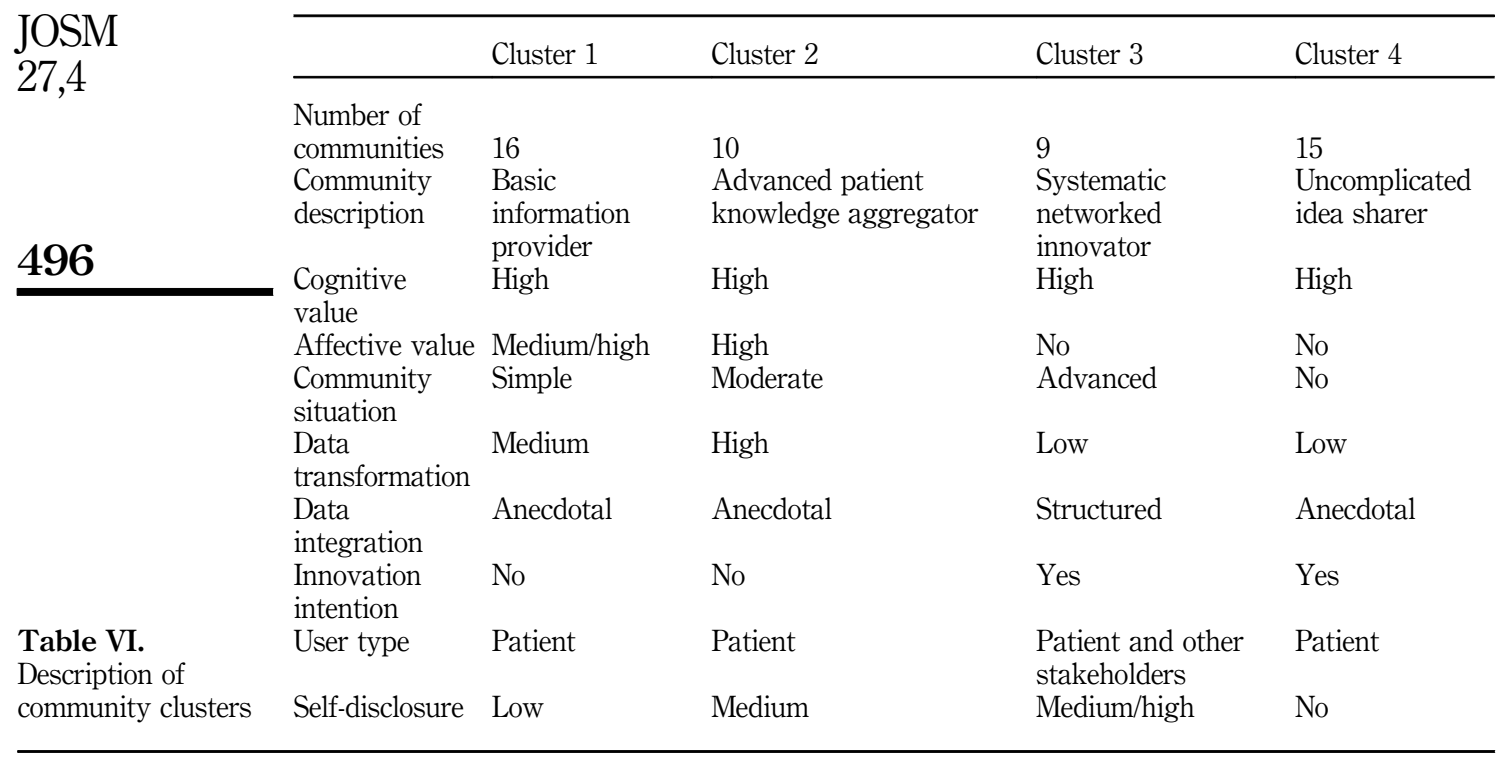

To manage their activities, these communities seek to provide tools to support data transformation. Similar to Cluster 1 , they focus solely on patients, but they offer a medium level of self-disclosure by adding general disease information to basic sociodemographic information. Communities in Cluster 2 create high value on a cognitive and affective level, such as on soberrecovery.com, a platform that combines discussion forums, blogs, chat, and personal messages to aid people trying to overcome drug and alcohol addictions (SoberRecovery, 2014). This cluster consists of advanced patient knowledge aggregators.

The most prominent characteristic of Cluster 3 is its structured focus on innovation for patients and other stakeholders. The diversity of actors enriches community content by combining various opinions. They engage in advanced sharing of the community situation, but they provide relatively few tools for data transformation. These communities focus on satisfying patient needs by combining several activities at an advanced level. Furthermore, because of their search for innovation, they focus on both patients and other stakeholders, creating high cognitive value but no affective value. The possibilities for self-disclosure are medium to high, because they add general and specific disease information in profiles. A prominent example is patientslikeme.com, where patients share their health data in a structured way (i.e. via an online profile) with peers and other stakeholders for innovation purposes (PLM, 2013). The authors refer to this cluster as systematic networked innovators.

Cluster 4 is dominated by anecdotal, patient-oriented innovation. A low level of sharing the community situation combines low data transformation and no selfdisclosure. These communities mainly focus on innovation as their core activity, which facilitates their management. Because they target only patients, similarity in the community is high, which fosters participation. Similar to Cluster 1 , these communities require only a low level of self-disclosure. They create high cognitive value but no affective value. The project of patient- innovation.com, for example, is a social network to facilitate sharing of innovative solutions to any disease, as developed by patients 
and caregivers (PatientInnovation, 2014). The patients and caregivers share stories of how they resolved the inconveniences of living with a certain pathology. The authors designate members of this cluster uncomplicated idea sharers.

\section{Relationship of clusters with cognitive and affective value}

Because cognitive and affective value are central outcomes for online health communities (Chronister et al., 2006; Zainuddin et al., 2013), the authors investigate how different community configurations might relate to the nature of value creation: cognitive (i.e. exchanging comprehensible information, advice, guidance) and/or affective (i.e. expressions of affection, listening, and sharing concerns). First, all clusters exhibit a high level of cognitive value. The question of the synergistic or conflicting nature of cognitive and affective value thus can be answered by reaching a high level of cognitive value, combined with varying levels of affective value. This finding seems logical, in that the main reason people go online is to find information, whereas social or affective relationships develop only over time (Saarni, 1999), when there is enough trust established between the participants. Providing cognitive value is a basic condition for attracting participants. Second, clusters that focus on the community situation and data transformation and integration provide medium to high levels of affective value. In these cases, the main reason to visit the community might be the need for cognitive value, while affective value develops. Third, clusters that focus on innovation and idea sharing do not provide any affective value. The main focus of these communities is engaging patients in the development of healthcare products and services, leaving little room for affective value.

\section{Discussion and research implications}

The authors conceptualize and empirically account for heterogeneity in online health communities by identifying four clusters that reflect the key components of coordination theory. From a theoretical perspective, this paper thus advances research in digital service provision by adopting a multidisciplinary approach. By combining coordination theory, as has been applied in various research disciplines with healthcare (Chronister et al., 2006), service (Vargo and Lusch, 2004), and knowledge creation (Nonaka, 1994) literature, the authors provide a fine-grained picture of the components of online health communities. A healthcare provider perspective is adopted by shedding light on the relationship between cognitive and affective value propositions. Previous research has remained inconclusive regarding the synergistic or conflicting nature of these two dimensions (Apesoa-Varano et al., 2011; De Valck et al., 2001), but this research indicates that cognitive value might be an enabler of affective value creation. Providing information thus offers a vital prerequisite for creating an online health community; affective value might be optional. Patients are drawn to online communities to find information, but over time, they could potentially develop a strong affective connection with their fellow participants and thus engage in the exchange of affective information (Saarni, 1999). The authors explored this premise by gathering and analyzing additional data. A significant, positive correlation (Spearman's $\rho: 0.319$, $p<0.05)$ between community age and the degree of affective value suggests that affective value might develop over time in online health communities. The study's capturing of a dual value proposition advances research on coordination theory which has focussed on cognitive (e.g. Edgington et al., 2010; Janssen and Bodemer, 2013; Purohit et al., 2014) and relational value (Faraj and Sproull, 2000; Faraj and Xiao, 2006; 
JOSM

27,4

498

Gittell, 2002) but omitted affective value. However, patients also seek care, or in other words affective value, from their healthcare services (Apesoa-Varano et al., 2011; De Valck et al., 2001). This is in line with existing services research that points toward the importance of cognitive and affective value delivered by the service provider (Dholakia et al., 2009). The findings highlight that activities related to data transformation such as wide presence of communication and visualization features to express members' experience correspond with affective goals of the community. Intriguingly, affective goals seem less relevant when the community is aimed at supporting innovation.

The study findings contribute to coordination theory by applying its components on online health communities, thereby identifying four trade-offs. First, the authors demonstrate that cognitive and affective value is synergetic rather than conflicting. Moreover, cognitive value seems to be a necessary condition in order to develop affective value. Second, the different activities installed in the community pose management challenges. However, by connecting these activities to cognitive and affective value, this research provides insights in the combination of activities that foster cognitive and affective value. Third, diversity in actors seems to be vital for communities that focus on structured innovation (i.e. cluster 3), while a sole focus on the patient and thereby increased similarity is important in the other community clusters. Fourth, privacy issues vs trust building is balanced by allowing in general low to medium level of self-disclosure.

Our findings demonstrate that communities can be categorized along two knowledge creation dimensions: knowledge externalization and knowledge internalization. These dimensions coincide with Nonaka's (1994) knowledge creation framework. Knowledge externalization relates to the extent to which a community provides tools to externalize the knowledge that members possess and transform tacit knowledge into explicit knowledge. For example, a community member who fills out a community profile externalizes knowledge about her or his individual situation. Using data transformation tools such as a discussion forum, she or he might communicate with others and transform her or his tacit knowledge into explicit knowledge, which then can be shared with other patients. Knowledge internalization instead focusses on who contributes knowledge and how this knowledge gets internalized and used, or the conversion from explicit to tacit knowledge. For example, updates about the community situation can aid patients in finding the right information at the right moment, such that it fosters knowledge internalization. The provision of innovation tools helps them probe other members' ideas and learning, so that these members can internalize others' knowledge. Finally, the user type describes the nature of the users who use community tools to internalize knowledge.

This study indicates that online health communities have the potential to satisfy unmet patient needs and support patient involvement during service delivery and medical decision making. However, these abilities might not always be favorable. Better informed patients likely demand more time during their patient-doctor encounters. Treating informed patients might be time efficient, in that they better understand their doctor's explanations, but they also might want to exhibit their knowledge or have additional questions (Fang et al., 2008). Better informed patients also might choose to follow their own beliefs, rather than those of their knowledgeable doctors, which undermines the doctor's authority and could have a strong detrimental effect on their health (Fang et al., 2008). Such potential negative effects of the online health communities and the empowered patients in general offer interesting avenue for future service research. 
The current study contributes to several service research topics. First, the authors provide more insights into coordinating value co-creation in a collaborative context. By applying coordination theory, the authors shed light on the components of online health communities and their interaction. Second, this study supports the enhancement of the service experience. Rather than focussing on the service experience of the individual patient, the authors investigate the role of patient communities and how to best develop and coordinate these communities that have positive outcomes for both patients and firms. Third, the authors demonstrate that online health communities are able to satisfy unmet patient needs, thereby contributing to transformative service research (Ostrom et al., 2015).

\section{Managerial implications}

Most life science professionals acknowledge that their company is using or plans to use online social networks (Deloitte, 2014). However, to implement digital services successfully, value-based segmentation is required, so companies need a good understanding of what drives the value created by their services (McKinsey and Co., 2014). This research provides a clear segmentation for online health communities and specifies what activities need to be in place to create cognitive and affective value. In doing so, this paper reveals that coordination theory is a useful framework for managers to organize and manage activities in online communities. In turn, three management entities are distinguished that might benefit from this research: community managers, other stakeholders (e.g. healthcare organizations and patient organizations), and policy makers.

First, the framework proposed in this paper grants community managers a good overview of the activities that they might implement to achieve the community's goals. Because cognitive value enables affective value in online communities, digital service providers should strongly encourage the exchange of factual information, advice, and guidance. Providing articles and blogs written by professionals may trigger discussions and shared treatment experiences among community members. When sufficient trust is established, affective relationships can develop, which in turn support the exchange of affective value. The community host also can foster affective value creation through anecdotal data integration and data transformation features. A moderator in online discussions can ask specific questions and probe participants' emotions, which should evoke affective value. Giving patients a place to tell their "story" also increases knowledge among their peers about their background and previous experiences. In turn, it becomes easier for those peers to empathize with fellow participants and respond in an effective way. Hence, to successfully deliver digital services such as online communities, community managers should first focus on activities that foster cognitive value, followed by activities that stimulate affective value.

Second, other stakeholders (e.g. pharmaceutical companies, developers of medical devices, research institutions and patient organizations) can collaborate with existing online communities for research and education purposes. But they should seek to tap communities whose activities align with the goals of the community (i.e. cognitive and affective value). A healthcare organization that is mainly interested in gathering factual information for service improvement should not probe Clusters 1 or 2 but rather focus on communities in Clusters 3 and 4, for example. Patient organizations, however, that aim to educate patients in combination with the provision of social support should probe Clusters 1 and 2, rather than Clusters 3 and 4.
Cognitive and affective value creation 
JOSM

27,4

500

Third, policy makers should address the conflict between trust and privacy issues. This research indicates that three of four clusters use self-disclosure to support trust. In 1996, the USA passed the Health Insurance Portability and Accountability Act (HIPAA), which requires protections of patients' identity and personal health information (HHS, 2015). However, online health communities are not among the entities covered by HIPAA, so they can bypass its mandates (HHS, 2015). Further regulation is needed to keep up with these developments and ensure that online community managers use patients' data in an appropriate and ethical way (Kluge, 2000).

\section{Limitations and further research}

Online health communities are an emerging phenomenon. Continued research should include emerging communities and conduct more extensive, quantitative analyses to validate these results. Furthermore, the authors deduced the value created in online communities from their mission statements and observations of community activities. Additional research might solicit the perceptions of community members through surveys too. This paper focussed on patient-centered communities, with limited interference from professionals or other stakeholders, so it might be interesting to investigate professional-oriented communities. Previous research indicates that physician networks are characterized by overspending (Hammerschmidt et al., 2012); online professional communities might help cut costs for end consumers and patients. Investigating how the key components of coordination theory emerge and how professional communities deal with their inherent conflicts could provide strong potential for improving resource utilization patterns. Furthermore, this paper focusses on the creation of cognitive and affective value as main goals of online health communities. However, other types of value might occur in these communities such as ethical, status and esteem value, as described by Holbrook (1999). Consequently, future research might look into these value types as goals of online health communities.

Finally, beyond either patients or their healthcare professionals, taking the perspective of the community host and investigating communities' business models might add more understanding of how different community configurations pertain to cognitive and affective value.

\section{References}

Adams, S.A. (2011), "Sourcing the crowd for health services improvement: the reflexive patient and 'share-your-experience' websites”, Social Science \& Medicine, Vol. 72 No. 7, pp. 1069-1076.

Apesoa-Varano, E.C., Barker, J.C. and Hinton, L. (2011), "Curing and caring: the work of primary care physicians with dementia patients", Qualitative Health Research, Vol. 21 No. 11, pp. 1469-1483.

Bagozzi, R.P. and Dholakia, U.M. (2002), "Intentional social action in virtual communities", Journal of Interactive Marketing, Vol. 16 No. 2, pp. 2-21.

Bain and Co. (2012), "The future of healthcare - there's an app for that", available at: www.bain. com/publications/articles/the-future-of-healthcare.aspx (accessed June 10, 2015).

Bansal, G., Zahedi, F. and Gefen, D. (2010), "The impact of personal dispositions on information sensitivity, privacy concern and trust in disclosing health information online", Decision Support Systems, Vol. 49 No. 2, pp. 138-150. 
Beatty, S.E., Mayer, M., Coleman, J.E., Reynolds, K.E. and Lee, J. (1996), "Customer-sales associate retail relationships", Journal of Retailing, Vol. 72 No. 3, pp. 223-247.

Berry, L.L. and Bendapudi, N. (2007), "Health care: a fertile field for service research", Journal of Service Research, Vol. 10 No. 2, pp. 111-122.

Bullinger, A.C., Rass, M., Adamczyk, S., Moeslein, K.M. and Sohn, S. (2012), "Open innovation in health care: analysis of an open health platform”, Health policy, Vol. 105 No. 2, pp. 165-175.

Camacho, N., Landsman, V. and Stremersch, S. (2009), "The connected patient", in Wuyts, S., Dekimpe, M.G., Gijsbrechts, E. and Pieters, F.R. (Eds), The Connected Customer: The Changing Nature of Consumer and Business Markets, Routledge Academic, Hampshire, pp. 107-140.

Chandler, J.D. and Lusch, R.F. (2015), "Service systems: a broadened framework and research agenda on value propositions, engagement, and service experience", Journal of Service Research, Vol. 18 No. 1, pp. 6-22.

Chronister, J.A., Johnson, E.K. and Berven, N.L. (2006), "Measuring social support in rehabilitation”, Disability \& Rehabilitation, Vol. 28 No. 2, pp. 75-84.

Cline, R. and Haynes, K. (2001), "Consumer health information seeking on the internet: the state of the art", Health Education Research, Vol. 16 No. 6, pp. 671-692.

Colvin, J., Chenoweth, L., Bold, M. and Harding, C. (2004), "Caregivers of older adults: advantages and disadvantages of internet-based social support", Family Relations, Vol. 53 No. 1, pp. 49-57.

Corbin, J. and Strauss, A. (2015), Basics of Qualitative Research: Techniques and Procedures for Developing Grounded Theory, Sage Publications.

Dahlin, K.B., Weingart, L.R. and Hinds, P.J. (2005), "Team diversity and information use", Academy of Management Journal, Vol. 48 No. 6, pp. 1107-1123.

Dannecker, A. and Lechner, U. (2007), "Online and offline integration in virtual communities of patients - an empirical analysis", paper presented at the 3rd International Conference on Communities and Technologies, East Lansing, MI.

De Valck, C., Bensing, J., Bruynooghe, R. and Batenburg, V. (2001), "Cure-oriented versus careoriented attitudes in medicine", Patient Education and Counseling, Vol. 45 No. 2, pp. 119-126.

Deloitte (2014), "Healthcare and life sciences predictions 2020 a bold future?", available at: www2. deloitte.com/content/dam/Deloitte/global/Documents/Life-Sciences-Health-Care/gx-lshchealthcare-and-life-sciences-predictions-2020.pdf (accessed December 2, 2014).

Demiris, G. (2006), "The diffusion of virtual communities in health care: concepts and challenges", Patient Education and Counseling, Vol. 62 No. 2, pp. 178-188.

Denzin, N.K. (1970), The Research Act In Sociology: A Theoretical Introduction To Sociological Methods, Buttersworth, London.

Dholakia, U.M., Blazevic, V., Wiertz, C. and Algesheimer, R. (2009), "Communal service delivery how customers benefit from participation in firm-hosted virtual P3 communities", Journal of Service Research, Vol. 12 No. 2, pp. 208-226.

Ebner, W., Leimeister, J.M. and Krcmar, H. (2004), "Trust in virtual healthcare communities: design and implementation of trust-enabling functionalities", paper presented at the Annual Hawaii International Conference on System Sciences, Los Alamitos, CA.

Ebner, W., Leimeister, J.M. and Krcmar, H. (2009), "Community engineering for innovations: the ideas competition as a method to nurture a virtual community for innovations", R\&D Management, Vol. 39 No. 4, pp. 342-356.

Edgington, T.M., Raghu, T. and Vinze, A.S. (2010), "Using process mining to identify coordination patterns in IT service management", Decision Support Systems, Vol. 49 No. 2 , pp. 175-186. 
JOSM

27,4

502

Euerby, A. and Burns, C.M. (2014), "Improving social connection through a communities of practice-inspired cognitive work analysis approach", Human Factors: The Journal of the Human Factors and Ergonomics Society, Vol. 56 No. 2, pp. 361-383.

Eysenbach, G., Powell, J., Englesakis, M., Rizo, C. and Stern, A. (2004), "Health related virtual communities and electronic support groups: systematic review of the effects of online peer to peer interactions", British Medical Journal, Vol. 328 No. 7449, pp. 1160-1170.

Fang, H., Miller, N.H., Rizzo, J.A. and Zeckhauser, R.J. (2008), "Demanding customers: consumerist patients and quality of care", The B.E. Journal of Economic Analysis \& Policy, Vol. 11 No. 1, pp. 1635-1682.

Faraj, S. and Sproull, L. (2000), "Coordinating expertise in software development teams", Management Science, Vol. 46 No. 12, pp. 1554-1568.

Faraj, S. and Xiao, Y. (2006), “Coordination in fast-response organizations”, Management Science, Vol. 52 No. 8, pp. 1155-1169.

Gemeinsamselten (2012), "Wir machen die Seltenen mobil", available at: www.Gemeinsamselten.de (accessed December 22, 2014).

Germtrax (2012), "Tracking the spread of sickness and disease”, available at: www.germtrax.com/ (accessed October 11, 2014).

Gittell, J.H. (2002), “Coordinating mechanisms in care provider groups: relational coordination as a mediator and input uncertainty as a moderator of performance effects", Management Science, Vol. 48 No. 11, pp. 1408-1426.

Gustafson, D.H., Hawkins, R., Boberg, E., Pingree, S., Serlin, R.E., Graziano, F. and Chan, C.L. (1999), "Impact of a patient-centered, computer-based health information/support system", American Journal of Preventive Medicine, Vol. 16 No. 1, pp. 1-9.

Gwinner, K.P., Gremler, D.D. and Bitner, M.J. (1998), "Relational benefits in services industries: the customer's perspective", Journal of the Academy of Marketing Science, Vol. 26 No. 2, pp. 101-114.

Hammerschmidt, M., Falk, T. and Staat, M. (2012), "Measuring and improving the performance of health service networks", Journal of Service Research, Vol. 15 No. 3, pp. 343-357.

Hayes, A.F. and Krippendorff, K. (2007), "Answering the call for a standard reliability measure for coding data", Communication Methods and Measures, Vol. 1 No. 1, pp. 77-89.

HHS (2015), "Health information privacy", available at: www.hhs.gov/ocr/privacy/ (accessed February 13, 2015).

Hoch, D. and Ferguson, T. (2005), "What I've learned from E-patients", PLoS Medicine, Vol. 2 No. 8, p. e206.

Holbrook, M.B. (1999), "Introduction to consumer value", in Holbrook, M.B. (Ed.), Consumer Value: A framework for Analysis and Research, Taylor \& Francis, London, pp. 1-28.

Innovationbyyou (2013), "Innovationbyyou", available at: www.Innovationbyyou.com (accessed October 5, 2013).

Inspire (2014), "Inspire Together we're better", available at: www.inspire.com/ (accessed October 10, 2014).

Jaakkola, E. and Alexander, M. (2014), "The role of customer engagement behavior in value co-creation: a service system perspective”, Journal of Service Research, Vol. 17 No. 3, pp. 247-261.

Janssen, J. and Bodemer, D. (2013), "Coordinated computer-supported collaborative learning: awareness and awareness tools", Educational Psychologist, Vol. 48 No. 1, pp. 40-55.

Jick, T.D. (1979), "Mixing qualitative and quantitative methods: triangulation in action", Administrative Science Quarterly, Vol. 24 No. 4, pp. 602-611. 
Johnson, G.J. and Ambrose, P.J. (2006), "Neo-tribes: the power and potential of online communities in health care", Communications of the ACM, Vol. 49 No. 1, pp. 107-113.

Keeling, D., Laing, A. and Newholm, T. (2015), "Health communities as permissible space: supporting negotiation to balance asymmetries", Psychology \& Marketing, Vol. 32 No. 3, pp. 303-318.

Kivits, J. (2006), "Informed patients and the internet a mediated context for consultations with health professionals", Journal of Health Psychology, Vol. 11 No. 2, pp. 269-282.

Kleijnen, M., Lievens, A., de Ruyter, K. and Wetzels, M. (2009), "Knowledge creation through mobile social networks and its impact on intentions to use innovative mobile services", Journal of Service Research, Vol. 12 No. 1, pp. 15-35.

Kluge, E.-H.W. (2000), "Professional codes for electronic HC record protection: ethical, legal, economic and structural issues", International Journal of Medical Informatics, Vol. 60 No. 2, pp. 85-96.

Kuenne, C.W., Moeslein, K.M. and Bessant, J. (2013), "Towards patients as innovators: open innovation in health care", in Akhilesh, K.B. and Iyer, P.P. (Eds), Driving the Economy through Innovation and Entrepreneurship, Springer, New Delhi, pp. 315-327.

LaVela, S.L. and Gallan, A.S. (2014), "Evaluation and measurement of patient experience", Patient Experience Journal, Vol. 1 No. 1, pp. 28-36.

Lee, F.S., Vogel, D. and Limayem, M. (2003), "Virtual community informatics: a review and research agenda", Journal of Information Technology Theory and Application, Vol. 5 No. 1, pp. 47-61.

Leimeister, J.M., Ebner, W. and Krcmar, H. (2005), "Design, implementation, and evaluation of trust-supporting components in virtual communities for patients", Journal of Management Information Systems, Vol. 21 No. 4, pp. 101-131.

Leimeister, J.M., Sidiras, P. and Krcmar, H. (2006), "Exploring success factors of virtual communities: the perspectives of members and operators", Journal of Organizational Computing and Electronic Commerce, Vol. 16 Nos 3-4, pp. 277-298.

Leimeister, J.M., Schweizer, K., Leimeister, S. and Krcmar, H. (2008), "Do virtual communities matter for the social support of patients? Antecedents and effects of virtual relationships in online communities”, Information Technology \& People, Vol. 21 No. 4, pp. 350-374.

Leonard, D. and Sensiper, S. (1998), "The role of tacit knowledge in group innovation”, California Management Review, Vol. 40 No. 3, pp. 112-132.

Loane, S.S. and D'Alessandro, S. (2013), "Peer-to-peer value through social capital in an online motor neuron disease community", Journal of Nonprofit \& Public Sector Marketing, Vol. 25 No. 2, pp. 164-185.

McColl-Kennedy, J.R., Vargo, S.L., Dagger, T.S., Sweeney, J.C. and van Kasteren, Y. (2012), "Health care customer value cocreation practice styles", Journal of Service Research, Vol. 15 No. 4, pp. 370-389.

McKinsey and Co. (2014), "Healthcare's digital future”, available at: www.mckinsey.com/insights/ health_systems_and_services/healthcares_digital_future (accessed December 6, 2014).

McMullan, M. (2006), "Patients using the internet to obtain health information: how this affects the patient-health professional relationship", Patient Education and Counseling, Vol. 63 No. 1, pp. 24-28.

McPherson, M., Smith-Lovin, L. and Cook, J.M. (2001), "Birds of a feather: homophily in social networks", Annual Review of Sociology, Vol. 27 No. 1, pp. 415-455.

McWilliam, G. (2012), "Building stronger brands through online communities", Sloan Management Review, Vol. 41 No. 3, pp. 43-54.

Mahr, D. and Lievens, A. (2012), "Virtual lead user communities: drivers of knowledge creation for innovation”, Research Policy, Vol. 41 No. 1, pp. 167-177.
Cognitive and affective value creation 
JOSM

27,4

504

Malone, T.W. and Crowston, K. (1990), "What is coordination theory and how can it help design cooperative work systems?", paper presented at the 1990 ACM Conference on ComputerSupported Cooperative Work, Los Angeles, CA, October 7-10.

Maloney-Krichmar, D. and Preece, J. (2005), "A multilevel analysis of sociability, usability, and community dynamics in an online health community", ACM Transactions on ComputerHuman Interaction, Vol. 12 No. 2, pp. 201-232.

Mascarenhas, O.A., Kesavan, R. and Bernacchi, M. (2004), “Customer value-chain involvement for co-creating customer delight”, Journal of Consumer Marketing, Vol. 21 No. 7, pp. 486-496.

Mathwick, C., Wiertz, C. and De Ruyter, K. (2008), "Social capital production in a virtual P3 community", Journal of Consumer Research, Vol. 34 No. 6, pp. 832-849.

Menary, R. (2007), “Writing as thinking”, Language Sciences, Vol. 29 No. 5, pp. 621-632.

Mo, P.K.H., Malik, S.H. and Coulson, N.S. (2009), "Gender differences in computer-mediated communication: a systematic literature review of online health-related support groups", Patient Education and Counseling, Vol. 75 No. 1, pp. 16-24.

Moeller, S., Ciuchita, R., Mahr, D., Odekerken-Schröder, G. and Fassnacht, M. (2013), "Uncovering collaborative value creation patterns and establishing corresponding customer roles", Journal of Service Research, Vol. 16 No. 4, pp. 471-487.

Nambisan, P. and Nambisan, S. (2009), "Models of consumer value cocreation in health care", Health Care Management Review, Vol. 34 No. 4, pp. 344-354.

National Center for Health Statistics (2012), "National ambulatory medical care survey: 2010 summary tables”, p. 35, available at: www.cdc.gov/nchs/data/ahcd/namcs_summary/ 2012_namcs_web_tables.pdf (accessed November 13, 2014).

Nonaka, I. (1994), “A dynamic theory of organizational knowledge creation”, Organization Science, Vol. 5 No. 1, pp. 14-37.

Odekerken-Schröder, G., Hennig-Thurau, T. and Knaevelsrud, A.B. (2010), "Exploring the post-termination stage of consumer-brand relationships: an empirical investigation of the premium car market”, Journal of Retailing, Vol. 86 No. 4, pp. 372-385.

Ong, L.M.L., De Haes, J.C.J.M., Hoos, A.M. and Lammes, F.B. (1995), "Doctor-patient communication: a review of the literature", Social Science \& Medicine, Vol. 40 No. 7, pp. 903-918.

Ostrom, A.L., Parasuraman, A., Bowen, D.E., Patrício, L. and Voss, C.A. (2015), "Service research priorities in a rapidly changing context", Journal of Service Research, Vol. 18 No. 2, pp. 127-159.

PatientInnovation (2014), "PatientInnovation", available at: https://patient-innovation.com/ (accessed October 10, 2014).

PatientOpinion (2013), "PatientOpinion", available at: www.patientopinion.org.uk (accessed September 25, 2014).

Pew Research Center (2013), "Health online 2013”, available at: www.pewinternet.org/ /media// Files/Reports/PIP_HealthOnline.pdf (accessed March 30, 2013).

Phelps, C., Heidl, R. and Wadhwa, A. (2012), "Knowledge, networks, and knowledge networks a review and research Agenda", Journal of Management, Vol. 38 No. 4, pp. 1115-1166.

PLM (2013), "Patients Like Me", available at: www.patientslikeme.com/ (accessed February 26, 2013).

Prahalad, C.K. and Ramaswamy, V. (2004a), “Co-creating unique value with customers”, Strategy \& Leadership, Vol. 32 No. 3, pp. 4-9.

Purohit, H., Hampton, A., Bhatt, S., Shalin, V.L., Sheth, A.P. and Flach, J.M. (2014), "Identifying seekers and suppliers in social media communities to support crisis coordination", Computer Supported Cooperative Work, Vol. 23 No. 4, pp. 513-545.

Ren, Y., Kraut, R. and Kiesler, S. (2007), "Applying common identity and bond theory to design of online communities”, Organization Studies, Vol. 28 No. 3, pp. 377-408. 
Ridings, C.M., Gefen, D. and Arinze, B. (2002), "Some antecedents and effects of trust in virtual communities”, Journal of Strategic Information Systems, Vol. 11 Nos 3-4, pp. 271-295.

Roberts, C.A. and Aruguete, M.S. (2000), "Task and socioemotional behaviors of physicians: a test of reciprocity and social interaction theories in analogue physician-patient encounters", Social Science \& Medicine, Vol. 50 No. 3, pp. 309-315.

Saarni, C. (1999), The Development of Emotional Competence, Guilford Press, New York, NY.

Schulz, U. and Schwarzer, R. (2004), "Long-term effects of spousal support on coping with cancer after surgery", Journal of Social and Clinical Psychology, Vol. 23 No. 5, pp. 716-732.

SoberRecovery (2014), “SoberRecovery”, available at: www.soberrecovery.com/ (accessed October 6, 2014).

Spiggle, S. (1994), "Analysis and interpretation of qualitative data in consumer research”, Journal of Consumer Research, Vol. 21 No. 3, pp. 491-503.

Stevenson, F.A., Kerr, C., Murray, E. and Nazareth, I. (2007), "Information from the internet and the doctor-patient relationship: the patient perspective-a qualitative study", BMC Family Practice, Vol. 8 No. 1, p. 47.

Stremersch, S. (2008), "Health and marketing: the emergence of a new field of research", International Journal of Research in Marketing, Vol. 25 No. 4, pp. 229-233.

Swan, M. (2009), "Emerging patient-driven health care models: an examination of health social networks, consumer personalized medicine and quantified self-tracking”, International Journal of Environmental Research and Public Health, Vol. 6 No. 2, pp. 492-525.

Sweeney, J.C., Danaher, T.S. and McColl-Kennedy, J.R. (2015), "Customer effort in value cocreation activities improving quality of life and behavioral intentions of health care customers", Journal of Service Research, Vol. 18 No. 2, pp. 1-18.

Turner, J.W., Grube, J.A. and Meyers, J. (2001), "Developing an optimal match within online communities: an exploration of CMC support communities and traditional support", Journal of Communication, Vol. 51 No. 2, pp. 231-251.

Vargo, S.L. (2008), "Customer integration and value creation: paradigmatic traps and perspectives", Journal of Service Research, Vol. 11 No. 2, pp. 211-215.

Vargo, S.L. and Lusch, R.F. (2004), "The four service marketing myths remnants of a goodsbased, manufacturing model”, Journal of Service Research, Vol. 6 No. 4, pp. 324-335.

Verma, R., Elg, M., Engström, J., Witell, L. and Poksinska, B. (2012), "Co-creation and learning in health-care service development", Journal of Service Management, Vol. 23 No. 3, pp. 328-343.

Vicdan, H. and Dholakia, N. (2013), "Medicine 2.0 and beyond: from information seeking to knowledge creation in virtual health communities", in Belk, R.W. and Llamas, R. (Eds), The Routledge Companion to Digital Consumption, Routledge, New York, NY, pp. 197-207.

Welbourne, J.L., Blanchard, A.L. and Wadsworth, M.B. (2013), "Motivations in virtual health communities and their relationship to community, connectedness and stress", Computers in Human Behavior, Vol. 29 No. 1, pp. 129-139.

Wilson, J.M., Straus, S.G. and McEvily, B. (2006), "All in due time: the development of trust in computer-mediated and face-to-face teams", Organizational Behavior and Human Decision Processes, Vol. 99 No. 1, pp. 16-33.

Zainuddin, N., Russell-Bennett, R. and Previte, J. (2013), "The value of health and wellbeing: an empirical model of value creation in social marketing", European Journal of Marketing, Vol. 47 No. 9, pp. 1504-1524.

Zhao, J., Wang, T. and Fan, X. (2015), "Patient value co-creation in online health communities: Social identity effects on customer knowledge contributions and membership continuance intentions in online health communities", Journal of Service Management, Vol. 26 No. 1, pp. 72-96.
Cognitive and affective value creation

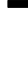


JOSM

27,4

Appendix

\begin{tabular}{|c|c|c|c|c|}
\hline ID & Name & Link & Health topic & Years \\
\hline 1 & CarePages & www.carepages.com/ & General & 15 \\
\hline 2 & What To Expect & www.whattoexpect.com & Specific: pregnancy & 18 \\
\hline 3 & Locate a Doc & www.locateadoc.com/ & Specific: plastic surgery & 17 \\
\hline 4 & Psychcentral & www.psychcentral.com & Specific: mental health & 24 \\
\hline 5 & Spark People & www.sparkpeople.com/ & General & 14 \\
\hline 6 & Spine Universe & www.spineuniverse.com/ & Specific: spine conditions & 16 \\
\hline 7 & 23andme & www.23andme.com & Specific: DNA testing & 9 \\
\hline 8 & Diabetic Connect & www.diabeticconnect.com & Specific: diabetes & 9 \\
\hline 9 & Dokter & www.dokter.nl & General & 10 \\
\hline 10 & E-health Forum & http://ehealthforum.com & General & 12 \\
\hline 11 & Gezondheid & www.gezondheid.be & General & 4 \\
\hline 12 & Health Boards & www.healthboards.com & General & 17 \\
\hline 13 & HealthMap & www.healthmap.org & General & 9 \\
\hline 14 & Flunearyou & https://flunearyou.org & Specific: flu & 4 \\
\hline 15 & Medwatcher & https://medwatcher.org & General & 5 \\
\hline 16 & HealthTap & www.healthtap.com & General & 5 \\
\hline 17 & Healthy Place & www.healthyplace.com/ & General & 15 \\
\hline 18 & I hadcancer & www.ihadcancer.com & Specific: cancer & 4 \\
\hline 19 & Inspire & www.inspire.com/ & General & 10 \\
\hline 20 & MDJunction & www.mdjunction.com & General & 9 \\
\hline 21 & Medhelp & www.medhelp.org & General & 21 \\
\hline 22 & Medisch Forum & http://medischforum.nl/ & General & 11 \\
\hline 23 & MedWonders & http://medwonders.com/ & General & 14 \\
\hline 24 & MumsNet & www.mumsnet.com & specific: pregnancy & 15 \\
\hline 25 & NetDoctor & www.netdoctor.co.uk & General & 7 \\
\hline 26 & NHS Choices & www.nhs.uk & General & 18 \\
\hline 27 & Patient Opinion & www.patientopinion.org.uk & General & 10 \\
\hline 28 & Patientslikeme & www.patientslikeme.com & General & 11 \\
\hline 29 & Propeller Health & http://propellerhealth.com/ & Specific: asthma and COPD & 5 \\
\hline 30 & Rate My Hospital & www.ratemyhospital.ie/ & General & 9 \\
\hline 31 & Sugarstats & www.sugarstats.com & Specific: diabetes & 9 \\
\hline 32 & The Body & www.thebody.com & Specific: AIDS/HIV & 20 \\
\hline 33 & Tudiabetes & www.tudiabetes.org & Specific: diabetes & 8 \\
\hline 34 & Vlaamse Liga tegen kanker & http://forum.tegenkanker.be/ & Specific: cancer & 10 \\
\hline 35 & WebMD & www.webmd.com & General & 19 \\
\hline 36 & Germtrax & www.germtrax.com/ & General & 3 \\
\hline 37 & ZocDoc & www.zocdoc.com & General & 8 \\
\hline 38 & Whatnext & www.whatnext.com & Specific: cancer & 4 \\
\hline 39 & Treato & www.treato.com & General & 8 \\
\hline 40 & Sixpartswater & www.sixpartswater.org & General & 8 \\
\hline 41 & Hearingjourney & http://hearingjourney.com/ & Specific: Cochlear implants & 9 \\
\hline 42 & Myglu & https://myglu.org/ & Specific: diabetes & 5 \\
\hline 43 & Patient.co.uk & www.patient.co.uk/ & General & 18 \\
\hline 44 & Patient Innovation & https://patient-innovation.com/ & General & 1 \\
\hline 45 & Soberrecovery & www.soberrecovery.com/ & Specific: drug rehabilitation & 15 \\
\hline 46 & The gooddrugsguide & www.thegooddrugsguide.com/ & Specific: drug rehabilitation & 14 \\
\hline 47 & Allaboutcounceling & www.allaboutcounseling.com/ & Specific: counseling & 17 \\
\hline 48 & Onehealth & www.onehealth.com/ & General & 5 \\
\hline 49 & Smartpatients & www.smartpatients.com/ & General & 5 \\
\hline 50 & Crohnology & https://crohnology.com/ & Specific: Crohn's and colitis & 7 \\
\hline
\end{tabular}

\section{Corresponding author}

Table AI.

Summary of online health communities investigated 